\title{
Formation of macrocyclic lactones in the Paternò-Büchi dimerization reaction
}

\author{
Junya Arimura ${ }^{1}$, Tsutomu Mizuta ${ }^{1}$, Yoshikazu Hiraga ${ }^{1}$ and Manabu Abe ${ }^{* 1,2}$
}

\section{Letter}

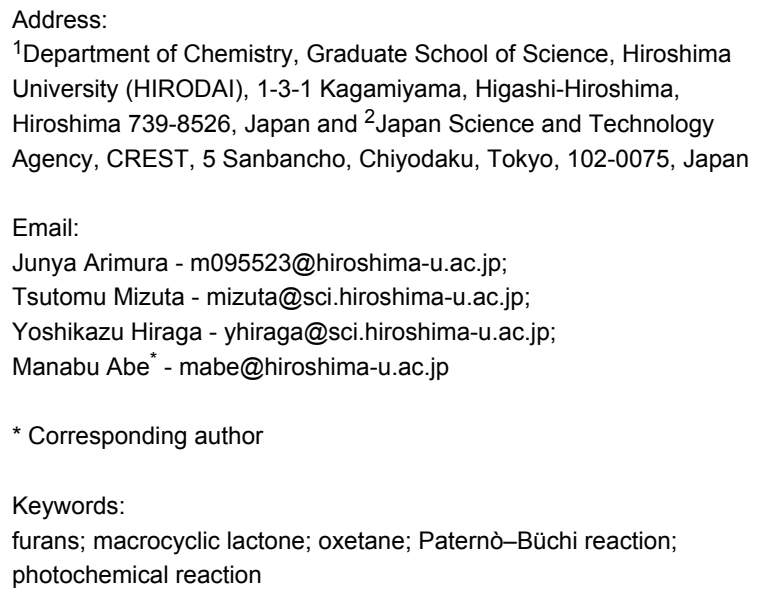

\author{
Beilstein J. Org. Chem. 2011, 7, 265-269. \\ doi:10.3762/bjoc.7.35 \\ Received: 11 November 2010 \\ Accepted: 02 February 2011 \\ Published: 28 February 2011 \\ This article is part of the Thematic Series "Photocycloadditions and \\ photorearrangements" \\ Guest Editor: A. G. Griesbeck \\ (C) 2011 Arimura et al; licensee Beilstein-Institut. \\ License and terms: see end of document.
}

\begin{abstract}
Furan-2-ylmethyl 2-oxoacetates $\mathbf{1 a}, \mathbf{b}$, in which the furan ring and the carbonyl moiety were embedded intramolecularly, were synthesized from commercially available furan-2-ylmethanol and their photochemical reaction ( $h v>290 \mathrm{~nm})$ was investigated. Twelve-membered macrocyclic lactones 2a,b with $C_{i}$ symmetry including two oxetane-rings, which are the Paternò-Büchi dimerization products, were isolated in ca. $20 \%$ yield. The intramolecular cyclization products, such as 3-alkoxyoxetane and 2,7-dioxabicyclo[2.2.1] hept-5-ene derivatives, were not detected in the photolysate.
\end{abstract}

\section{Findings}

Photochemical $[2+2]$ cycloaddition reaction of alkenes with carbonyls, so-called Paternò-Büchi reaction [1-13], is one of the most efficient methods for preparing synthetically useful four-membered heterocyclic compounds, i.e., oxetanes. The Paternò-Büchi reaction of furan with a triplet carbonyl, such as $\mathrm{n}, \pi^{*}$ triplet benzophenone, produces regioselectively 2-alkoxyoxetanes 20X (Scheme 1). The regioselective formation is rationalized by the relative stability of the intermediary triplet biradicals, BR versus BR', and also by the relative nucleo- philicity of the furan-ring carbons, i.e., C1 versus C2 (Scheme 1) [14-18].

Biradical BR, in principle, possess two resonance forms, i.e., 1,4-biradical form and 1,6-biradical form. The 1,4-biradical form affords oxetane 2OX after the intersystem crossing (ISC). Alternatively, 2,7-dioxabicyclo[2.2.1]hept-5-ene OBH would be formed from the 1,6-biradical form. The regioisomeric oxetane 3OX should be formed via the regioisomeric biradical 


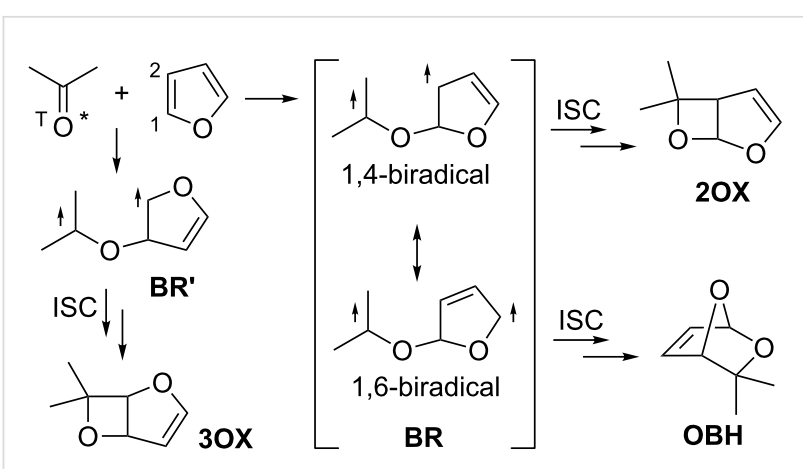

Scheme 1: Reaction of furan with triplet excited carbonyls, regioselectivity.

BR'. Biradical BR is energetically more stable than BR', because BR can undergo radical delocalization. The electrophilic oxygen of the excited carbonyl should preferably interact with more nucleophilic $\mathrm{C} 1$ carbon to give selectively the biradical BR. Thus, only the 2-alkoxyoxetane 2OX has been observed in the Paternò-Büchi reactions reported so far [19-27]. Thus, in this study, furan-2-ylmethyl 2-oxoacetates $\mathbf{1 a}, \mathbf{b}$ and 2-(furan-2-yl)ethyl 2-oxo-2-phenylacetate 1c [28] were synthesized, in which the furan ring and the carbonyl moiety are connected intramolecularly, and their photochemical reactions were investigated to see whether the reaction proceeds intramolecularly to produce the 3-alkoxyoxetane derivative $\mathbf{A}$ and/or the dioxabicyclo[2.2.1] hept-5-ene derivative $\mathbf{B}$, or intermolecularly to give the 2-alkoxyoxetane derivative $\mathbf{C}$ (Scheme 2).

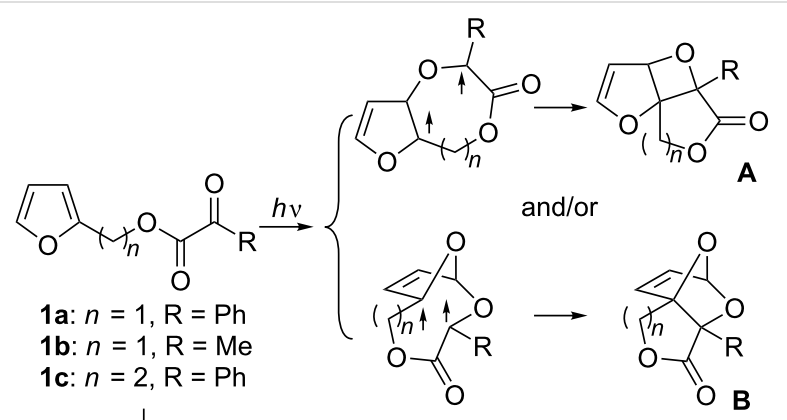

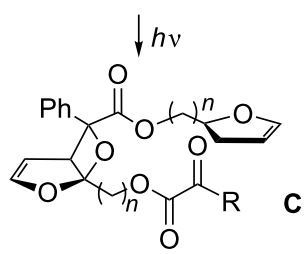

Scheme 2: Possible pathways for the photochemical reaction of furan derivatives $\mathbf{1 a - c}$.

Compounds 1a-c [28] were synthesized from furan-2ylmethanol or furan-2-ylethanol [29] (Scheme 3). Compound 1a $(\mathrm{R}=\mathrm{Ph})$ was irradiated in degassed benzene with a high-pressure Hg lamp with a Pyrex filter (Scheme 3). Interestingly, the

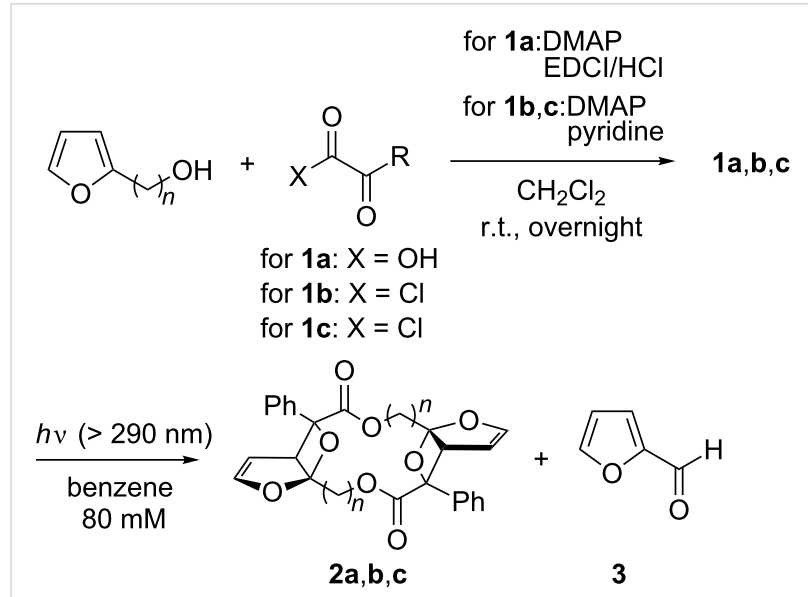

Scheme 3: Synthesis and the photochemical reaction of furan-2ylmethyl 2-oxoacetates 1a,b.

Paternò-Büchi dimer product $\mathbf{2 a}(\mathrm{R}=\mathrm{Ph})$, which possesses $C_{i}$ symmetry, was obtained as the major product and contains the biologically important macrocyclic lactone structure [30-33]. The structure of $\mathbf{2 a}$ was unequivocally determined by the X-ray crystallographic analysis (Figure 1). The one-step preparation of the highly functionalized twelve-membered macrocyclic lactone is synthetically attractive. Intramolecular products, such as compounds $\mathbf{A}$ and $\mathbf{B}$, were not detected in the photolysate, although intramolecular cyclization products are known to be products in the photoreaction of 3-substituted furan derivatives [11,21]. Furan-2-carbaldehyde (3) was the only assignable product during the photochemical reaction, which was monitored by ${ }^{1} \mathrm{H}$ NMR spectroscopy (Figure 2). The intermolecular Paternò-Büchi reaction product, i.e., $\mathbf{C}$ in Scheme 2, was also not observed in the photolysate. This result suggests that the

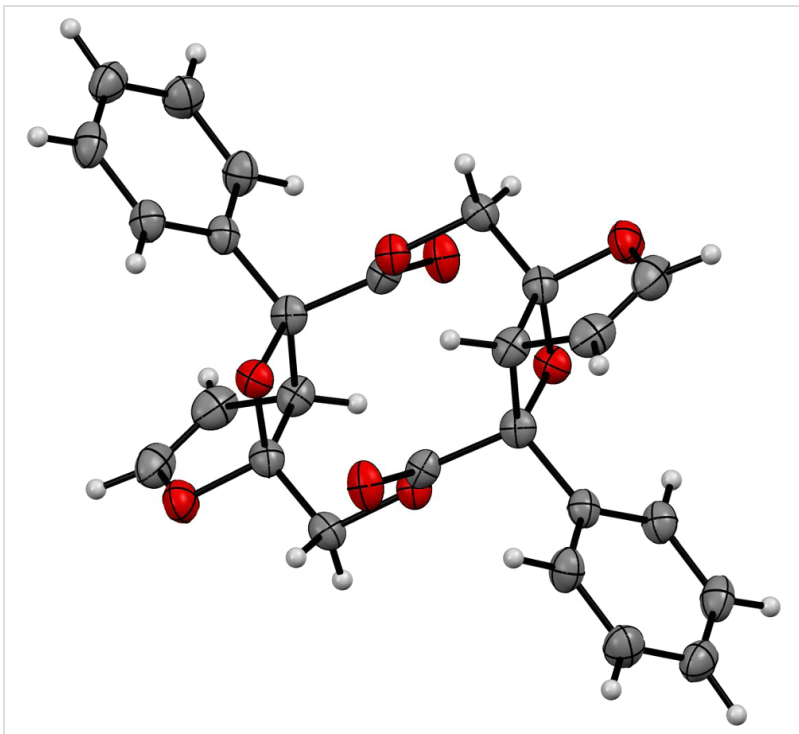

Figure 1: X-ray crystal structure of the macrocyclic lactone $\mathbf{2 a}$ 


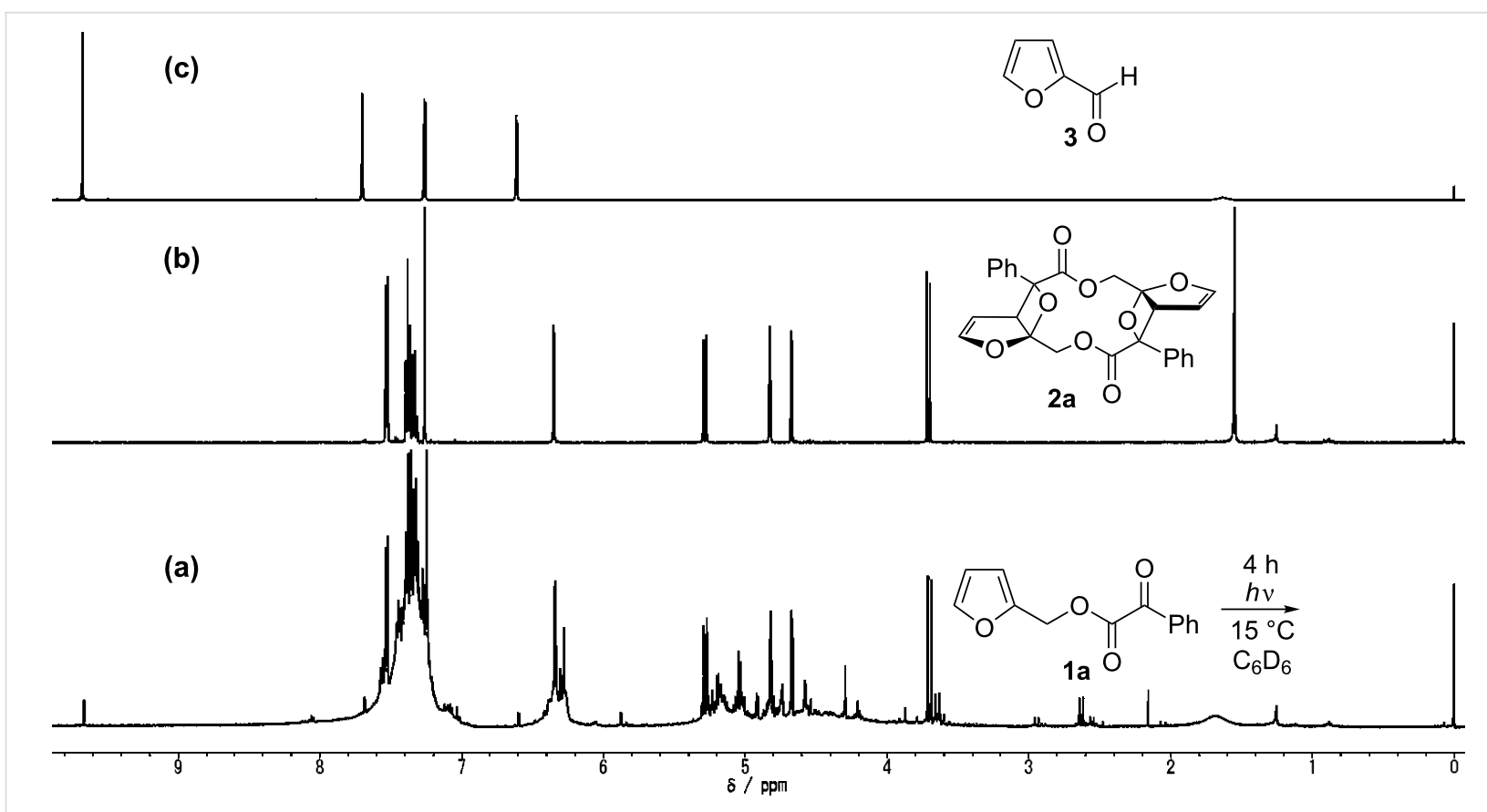

Figure 2: ${ }^{1} \mathrm{H}$ NMR spectra $(500 \mathrm{MHz})$ for $(\mathrm{a})$ the photolysate of $1 \mathrm{a}$ after $4 \mathrm{~h}$ irradiation in degassed and dried $\mathrm{C}_{6} \mathrm{D}_{6}$ solution, $(\mathrm{b})$ for isolated macrocyclic lactone $2 \mathrm{a}$, and (c) for furan-2-carbaldehyde (3).

intramolecular Paternò-Büchi reaction of $\mathbf{C}$ is faster than the first intermolecular Paternò-Büchi reaction of 1a. The photoreaction of $\mathbf{1 b}(\mathrm{R}=\mathrm{Me})$ gave $\mathbf{2 b}$ and $\mathbf{3}$ in $25 \%$ and $18 \%$, respectively (Scheme 3). The dimerization product 2c was not observed in the reaction of 1c. Only polymeric products were present in the photolysate. Although the dimerization is sensitive to the chain-length, the Paternò-Büchi dimerization reaction could in future be applicable to the synthesis of a variety of macrocyclic lactones.

To investigate the effects of concentration, solvent, and temperature on the formation of $\mathbf{2 a}$, the photochemical reaction of 1a was conducted under the variety of conditions (Table 1). The yield of intermolecular product $\mathbf{2 a}$ was expected to be improved when the concentration of 1 a was increased; however, no concentration effect was observed (entry 2). Under the reaction conditions, the formation of polymeric products increased as evidenced by ${ }^{1} \mathrm{H}$ NMR analysis of the photolysate. Even with low concentrations of 1a (entry 3), the intramolecular photoproducts $\mathbf{A}$ and $\mathbf{B}$ were not detected by ${ }^{1} \mathrm{H}$ NMR (500 MHz). To investigate the medium effect on the formation of $\mathbf{2 a}$, the photochemical reaction of $\mathbf{1 a}$ was performed in several solvents (entries 4-6). The yield of 2a decreased with increasing solvent polarity; $16 \%$ in toluene (entry 4 ) and $10 \%$ in $\mathrm{CH}_{3} \mathrm{CN}$ (entry 6). Temperature had no effect on the yield of 2a (entries 7-9).

In summary, the intramolecular products such as $\mathbf{A}$ and $\mathbf{B}$ were not observed in the photochemical reaction of furan derivatives

\begin{tabular}{|c|c|c|c|c|}
\hline entry & solvent & $\begin{array}{l}\text { concentration } \\
\text { of } 1 \mathrm{a}(\mathrm{mM})\end{array}$ & $\begin{array}{c}\text { temperature } \\
\left({ }^{\circ} \mathrm{C}\right)\end{array}$ & $\begin{array}{l}\text { yield of } \\
2 a(\%)^{b}\end{array}$ \\
\hline 1 & benzene & 80 & 15 & 18 \\
\hline 2 & benzene & 800 & 15 & 8 \\
\hline 3 & benzene & 8 & 15 & 17 \\
\hline 4 & toluene & 80 & 15 & 16 \\
\hline 5 & $\mathrm{CH}_{2} \mathrm{Cl}_{2}$ & 80 & 15 & 10 \\
\hline 6 & $\mathrm{CH}_{3} \mathrm{CN}$ & 80 & 15 & 10 \\
\hline 7 & benzene & 80 & 50 & 5 \\
\hline 8 & toluene & 80 & -35 & 18 \\
\hline 9 & toluene & 80 & -75 & 14 \\
\hline
\end{tabular}

aThe photochemical reactions of 1a were performed for $4 \mathrm{~h}$ with a high-pressure $\mathrm{Hg}$ lamp $(300 \mathrm{~W})$ with a Pyrex filter under a dry nitrogen atmosphere in dried and degassed solvent. ${ }^{b}$ The yields of $2 a$ were determined on the basis of ${ }^{1} \mathrm{H}$ NMR $(500 \mathrm{MHz})$ peak areas; error \pm $3 \%$. Dimethyl fumarate was used as an internal standard.

1a,b, but interestingly the Paternò-Büchi dimers $\mathbf{2 a}, \mathbf{b}$ with the $C_{i}$ symmetry, i.e., macrocyclic lactones, were isolated in ca. $20 \%$ yield. The results indicate that the intramolecular reactions, which produce 3-alkoxyoxetanes and 2,7-dioxabicyclo[2.2.1]hept-5-ene (Scheme 1 and Scheme 2), are slower than the intermolecular reaction which leads to the preferential formation of 2-alkoxyoxetane $\mathbf{C}$ which is followed by a second Paternò-Büchi reaction to give the observed macrocyclic lactones 2. This finding should stimulate future experimental 
and computational studies on the mechanistically and synthetically fascinating formation of macrocyclic lactone derivatives.

\section{Experimental}

NMR and MS measurements were made using JEOL JMNLA500 and Thermo Fisher Scientific LTD Orbitrap XL spectrometers, respectively, at the Natural Science Center for Basic Research and Development (N-BARD), Hiroshima University.

The furan derivatives $\mathbf{1 a}-\mathbf{c}(129 \mathrm{mg}, 0.561 \mathrm{mmol})$ were dissolved in benzene $(7.0 \mathrm{ml})$ and the degassed reaction mixture was irradiated with a high-pressure Hg lamp $(300 \mathrm{~W}, h v>$ $290 \mathrm{~nm}$ ) with a Pyrex filter. After $13 \mathrm{~h}$, the solvent was removed in vacuo and dimethyl fumarate added as an internal standard. ${ }^{1} \mathrm{H}$ NMR $\left(500 \mathrm{MHz}, \mathrm{CDCl}_{3}\right)$ was measured to determine the ratio of products. After the photoreaction, the residue was purified by repeated column chromatography and PTLC (hexane-EtOAc $=2: 1$ ) to give $\mathbf{2 a}, \mathbf{b}$ as colorless crystals.

2a: ${ }^{1} \mathrm{H}$ NMR $\left(500 \mathrm{MHz}, \mathrm{CDCl}_{3}\right) \delta 7.55-7.51(\mathrm{~m}, 4 \mathrm{H})$, $7.40-7.31(\mathrm{~m}, 6 \mathrm{H}), 6.35(\mathrm{dd}, J=3.1,1.1 \mathrm{~Hz}, 2 \mathrm{H}), 5.28(\mathrm{dd}, J=$ $12.5,0.9 \mathrm{~Hz}, 2 \mathrm{H}), 4.82(\mathrm{dt}, J=3.0,0.9 \mathrm{~Hz}, 2 \mathrm{H}), 4.67(\mathrm{dd}, J=$ $3.0,1.1 \mathrm{~Hz}, 2 \mathrm{H}), 3.71(\mathrm{~d}, J=12.5 \mathrm{~Hz}, 2 \mathrm{H}) ;{ }^{13} \mathrm{C} \mathrm{NMR}$ $\left(125 \mathrm{MHz}, \mathrm{CDCl}_{3}\right): \delta 171.6(\mathrm{C}), 148.7(\mathrm{CH}), 136.0(\mathrm{CH}), 128.6$ $(\mathrm{CH}), 128.4(\mathrm{CH}), 125.7(\mathrm{CH}), 112.6(\mathrm{C}), 102.1(\mathrm{CH}), 90.7(\mathrm{C})$, $61.4(\mathrm{CH} 2), 55.2(\mathrm{CH})$; HRMS (ESI) $\mathrm{m} / \mathrm{z}$ calcd for $\mathrm{C}_{26} \mathrm{H}_{20} \mathrm{O}_{8} \mathrm{Na}(\mathrm{M}+\mathrm{Na})^{+} 483.10504$, found 483.10526 .

2b: ${ }^{1} \mathrm{H}$ NMR (500 MHz, $\left.\mathrm{CDCl}_{3}\right): \delta 6.66(\mathrm{dd}, J=3.0,1.2 \mathrm{~Hz}$, $2 \mathrm{H}), 5.23(\mathrm{dt}, J=3.0,0.8 \mathrm{~Hz}, 2 \mathrm{H}), 5.14(\mathrm{dd}, J=12.5,0.8 \mathrm{~Hz}$, $2 \mathrm{H}), 4.27(\mathrm{dd}, J=3.0,1.2 \mathrm{~Hz}, 2 \mathrm{H}), 3.77$ (d, $J=12.5 \mathrm{~Hz}, 2 \mathrm{H})$, $1.57(\mathrm{~s}, 6 \mathrm{H}) ;{ }^{13} \mathrm{C}$ NMR $\left(125 \mathrm{MHz}, \mathrm{CDCl}_{3}\right): \delta 173.3(\mathrm{C}), 149.8$ $(\mathrm{CH}), 112.7(\mathrm{C}), 101.3(\mathrm{CH}), 88.1(\mathrm{C}), 61.5\left(\mathrm{CH}_{2}\right), 53.1(\mathrm{CH})$, $21.2\left(\mathrm{CH}_{3}\right)$; HRMS (ESI) $\mathrm{m} / z$ calcd for $\mathrm{C}_{16} \mathrm{H}_{16} \mathrm{O}_{8} \mathrm{Na}(\mathrm{M}+\mathrm{Na})^{+}$ 359.07374 , found 359.07391 .

\section{Supporting Information}

\section{Supporting Information File 1}

Experimental section for preparation of compounds 1a-c, the detail of the X-ray structure of compound $\mathbf{2 a}$, and ${ }^{1} \mathrm{H}$ NMR and ${ }^{13} \mathrm{C}$ NMR spectra for compounds $\mathbf{2 a}, \mathbf{b}$. [http://www.beilstein-journals.org/bjoc/content/ supplementary/1860-5397-7-35-S1.pdf]

\section{Supporting Information File 2}

$\mathrm{X}$-Ray crystallographic data for compound $\mathbf{2 a}$. [http://www.beilstein-journals.org/bjoc/content/ supplementary/1860-5397-7-35-S2.cif]

\section{Acknowledgements}

M. A. acknowledges financial support in the form of a Grant-inAid for Scientific Research on Innovative Areas " $\pi$-Space" (No 21108516), the Scientific Research (B) (No. 19350021), and Tokuyama Science Foundation.

\section{References}

1. Paternò, E.; Chieffi, G. Gazz. Chim. Ital. 1909, 39, 341-361.

2. Büchi, G.; Inman, C. G.; Lipinsky, E. S. J. Am. Chem. Soc. 1954, 76, 4327-4331. doi:10.1021/ja01646a024

3. Yang, N. C.; Nussim, M.; Jorgenson, M. J.; Murov, S. Tetrahedron Lett. 1964, 5, 3657-3664. doi:10.1016/S0040-4039(01)89388-6

4. Arnold, D. R. The Photocycloaddition of Carbonyl Compounds to Unsaturated Systems: The Syntheses of Oxetanes. In Advances in Photochemistry; Noyes, W. A.; Hammond, G. S.; Pitts, J. N., Eds.; John Wiley \& Sons, Inc.: Hoboken, NJ, USA, 1968; Vol. 6, pp 301-349. doi:10.1002/9780470133361.ch4

5. Carless, H. A. J. In Synthetic Organic Photochemistry; Horspool, W. M., Ed.; Plenum Press: New York, 1984; pp 425-487.

6. Griesbeck, A. G. Photochemical Oxetane Formation: Intermolecular Reactions. In CRC Handbook of Organic Photochemistry and Photobiology; Horspool, W. M.; Song, P.-S., Eds.; CRC Press: Boca Raton, 1995; pp 522-535.

7. Griesbeck, A. G. In CRC Handbook of Organic Photochemistry and Photobiology; Horspool, W. M.; Song, P.-S., Eds.; CRC Press: Boca Raton, 1995; pp 550-559.

8. Griesbeck, A. G.; Bondock, S. Oxetane Formation: Stereocontrol. In CRC Handbook of Organic Photochemistry and Photobiology, 2nd ed.; Horspool, W. M.; Lenci, F., Eds.; CRC Press: Boca Raton, 2004; chapter 59.

9. Griesbeck, A. G.; Bondock, S. Oxetane Formation: Intermolecular Additions. In CRC Handbook of Organic Photochemistry and Photobiology, 2nd ed.; Horspool, W. M.; Lenci, F., Eds.; CRC Press: Boca Raton, 2004; chapter 60.

10. Abe, M. Photochemical Oxetane Formation: Addition to Heterocycles. In CRC Handbook of Organic Photochemistry and Photobiology, 2nd ed.; Horspool, W. M.; Lenci, F., Eds.; CRC Press: Boca Raton, 2004; chapter 62.

11. Porco, J. A.; Schreiber, S. L. The Paternò-Büchi Reaction. In Comprehensive Organic Synthesis; Trost, B. M.; Fleming, I., Eds.; Pergamon Press: Oxford, 1991; Vol. 2, pp 151-192. doi:10.1016/B978-0-08-052349-1.00123-2

12. Bach, T. Synthesis 1998, 683-703. doi:10.1055/s-1998-2054

13. Hei, X.-M.; Song, Q.-H.; Li, X.-B.; Tang, W.-J.; Wang, H.-B.; Guo, Q.-X. J. Org. Chem. 2005, 70, 2522-2527. doi:10.1021/jo048006k

14. Abe, M.; Kawankami, T.; Ohata, S.; Nozaki, K.; Nojima, M. J. Am. Chem. Soc. 2004, 126, 2838-2846. doi:10.1021/ja039491o

15. Griesbeck, A. G.; Abe, M.; Bondock, S. Acc. Chem. Res. 2004, 37, 919-928. doi:10.1021/ar040081u

16. Abe, M. J. Chin. Chem. Soc. (Taipei, Taiwan) 2008, 55, 479-486.

17. Abe, M. Chapter 7. Formation of a Four-Membered Ring: Oxetanes. In Handbook of Synthetic Photochemistry; Albini, A.; Fagnoni, M., Eds.; Wiley-VCH: Weinheim, 2009; pp 217-239. doi:10.1002/9783527628193.ch7

18. Shima, K.; Sakurai, H. Bull. Chem. Soc. Jpn. 1966, 39, 1806-1808. doi:10.1246/bcsj.39.1806

19. Whipple, E. B.; Evanega, G. R. Tetrahedron 1968, 24, 1299-1310. doi:10.1016/0040-4020(68)88081-0 
20. Jarosz, S.; Zamojski, A. Tetrahedron 1982, 38, 1447-1451. doi:10.1016/0040-4020(82)80228-7

21. Schreiber, S. L.; Hoveyda, A. H.; Wu, H.-J. J. Am. Chem. Soc. 1983, 105, 660-661. doi:10.1021/ja00341a077

22. Cantrell, T. S.; Allen, A. C.; Ziffer, H. J. Org. Chem. 1989, 54, 140-145. doi:10.1021/jo00262a032

23. Hambalek, R.; Just, G. Tetrahedron Lett. 1990, 31, 5445-5448. doi:10.1016/S0040-4039(00)97868-7

24. Griesbeck, A. G.; Buhr, S.; Fiege, M.; Schmickler, H.; Lex, J. J. Org. Chem. 1998, 63, 3847-3854. doi:10.1021/jo971767।

25. Hu, S.; Neckers, D. C. J. Chem. Soc., Perkin Trans. 2 1999, 1771-1778. doi:10.1039/a901092k

26. D’Auria, M.; Racioppi, R.; Romaniello, G. Eur. J. Org. Chem. 2000, 3265-3272. doi:10.1002/1099-0690(200010)2000:19<3265::AID-EJOC3265>3.0.C O;2-6

27. Zhang, Y.; Xue, J.; Gao, Y.; Fun, H.-K.; Xu, J.-H. J. Chem. Soc., Perkin Trans. 1 2002, 345-353. doi:10.1039/B109697D

28. Howard, B. E.; Woerpel, K. A. Tetrahedron 2009, 65, 6447-6453. doi:10.1016/j.tet.2009.05.066

29. Loiseau, F.; Simone, J.-M.; Carcache, D.; Bobal, P.; Neier, R. Monatsh. Chem. 2007, 138, 121-129. doi:10.1007/s00706-006-0578-x

30. Miyauchi, H.; Ikematsu, C.; Shimazaki, T.; Kato, S.; Shinmyozu, T.; Shimo, T.; Somekawa, K. Tetrahedron 2008, 64, 4108-4116. doi:10.1016/j.tet.2008.02.005

31. Denmark, S. E.; Muhuhi, J. M. J. Am. Chem. Soc. 2010, 132, 11768-11778. doi:10.1021/ja1047363

32. Wang, X.; Porco, J. A., Jr. J. Am. Chem. Soc. 2003, 125, 6040-6041. doi:10.1021/ja034030o

33. Molander, G. A.; Dehmel, F. J. Am. Chem. Soc. 2004, 126, 10313-10318. doi:10.1021/ja047190o

\section{License and Terms}

This is an Open Access article under the terms of the Creative Commons Attribution License (http://creativecommons.org/licenses/by/2.0), which permits unrestricted use, distribution, and reproduction in any medium, provided the original work is properly cited.

The license is subject to the Beilstein Journal of Organic Chemistry terms and conditions:

(http://www.beilstein-journals.org/bjoc)

The definitive version of this article is the electronic one which can be found at: doi:10.3762/bjoc. 7.35 